\title{
Religião, moral e civismo em curso: \\ a marcha da socialização política
}

\section{Religion, morals and civism in progress:}

the march of political socialization

\section{Religión, moral y civismo en curso: \\ la marcha de la socialización política}

\section{LUIZ ANTÔNIO CUNHA*}

RESUMO: Oartigo analisa os projetos de socialização política no Brasil atual: a regeneração moral via especialização curricular e a militarização escolar para o controle social. Em contraste com a sintonia oscilante prevalecente na relação entre o ensino religioso nas escolas públicas e a educação moral e cívica nas públicas e nas privadas, nas décadas precedentes, o autor prevê uma dessintonia conflitante nos domínios da pedagogia e da gestão dos sistemas escolares.

Palavras-chave: Políticas educacionais. Socialização política. Ensino religioso. Educação moral e cívica. Escolas cívico-militares

\begin{abstract}
The article analyzes the political socialization projects in present Brazil: moral regeneration via curricular specialization and school militarization for social control. In contrast to the oscillating syntony prevailing in the relationship between religious education in public schools and moral and civic education in public and private schools, in the preceding decades, the author foresees a conflicting disharmony in the realms of pedagogy and school systems management.
\end{abstract}

* Sociólogo, Mestre em Planejamento Educacional pela Pontifícia Universidade Católica do Rio de Janeiro e Doutor em Filosofia da Educação pela Pontifícia Universidade Católica de São Paulo. Exerceu magistério na Pontifícia Universidade Católica do Rio de Janeiro, na Fundação Getúlio Vargas, na Universidade Estadual de Campinas, na Universidade Federal Fluminense e na Universidade Federal do Rio de Janeiro. E-mail:<lacunha@pesquisador.cnpq.br>. 
Keywords: Educational policies. Political socialization. Religious education moral and civic education. Civic-military schools.

RESUMEN: El artículo analiza los proyectos de socialización política en el Brasil hoy: la regeneración moral a través de la especialización curricular y la militarización escolar para el control social. En contraste con la sintonía oscilante que prevalece en la relación entre la enseñanza religiosa en las escuelas públicas y la educación moral y cívica en las escuelas públicas y privadas en décadas anteriores, el autor predice una desarmonía conflictiva en los dominios de la pedagogía y la gestión de sistemas escolares.

Palabras clave: Políticas educacionales. Socialización política. Educación religiosa. Educación moral y cívica. Escuelas cívico-militares

\section{Introdução}

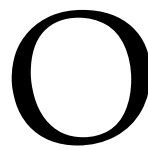

s processos espontâneos e induzidos pelos quais se desenvolve a socialização política, isto é, a interiorização de normas, valores e atitudes relativos à percepção do campo político e ao comportamento neste campo (LANGROYE et al., 2006, p. 409), constituem um dos elementos menos estudados da sociologia da educação no Brasil. Ela se dá toda na infância (com o papel da escola, da família e das entidades religiosas) ou se desenvolve ao longo de toda a vida (com os meios de comunicação de massa, os partidos e os movimentos sociais). Essas questões não serão tratadas aqui, malgrado sua relevância. ${ }^{1}$

Minha atenção está voltada para os projetos de socialização política integrantes de políticas educacionais pautadas pelos conflitos no interior do campo político e do campo religioso, bem como da interação entre eles. Portanto, estarei atento aos processos induzidos de socialização política. Para tanto, ampliarei o ângulo de visão da socialização, já que, no Brasil (mas não só aqui, com certeza), não é possível compreender política e religião sem levar em conta a forte imbricação entre elas, inclusive e principalmente se o objeto é a educação.

Assim é que o ensino religioso (ER) será tratado em interação com a educação moral e cívica (EMC). Por fim, apresento elementos das ciências sociais que podem ajudar na previsão da eficácia de tais políticas. 


\section{Sintonia oscilante}

Nas quatro primeiras décadas da República, o ER foi suprimido das escolas públicas, por determinação expressa da Constituição de 1891. No seu lugar foi introduzida no ensino primário e/ou no secundário, em alguns momentos, a disciplina moral (sem o complemento "e cívica"), de feição positivista. A reforma João Luiz Alves/Rocha Vaz (Decreto nº 16.782-A/1925) trouxe a instrução moral e cívica (EMC) para o currículo do ensino secundário, onde ocuparia o lugar da religião.

Nenhum dos grupos políticos que desfecharam a revolução de 1930 logrou hegemonia sobre as forças heterogêneas que dela se beneficiaram. O espaço político daí resultante foi ocupado pela Igreja Católica, atraída para o esquema de sustentação do Governo Provisório pelo Decreto nº 19.941/1931, que permitiu o oferecimento do ER em regime facultativo para os alunos, nos estabelecimentos públicos de ensino primário, secundário, profissional e normal. A EMC, prevista na reforma de 1925, foi suprimida dos currículos com a justificação de que os valores que se pretendiam transmitir já estavam contemplados pela religião. A vitória alcançada pela Igreja Católica com a promulgação desse decreto foi potencializada na Constituição de 1934. As escolas públicas primárias, secundárias, profissionais e normais eram obrigadas a oferecer o ER, que continuava facultativo para os alunos, pelo menos formalmente.

Do ER substituindo a EMC passou-se, no Estado Novo (1937-1945), à sintonia entre ambas as disciplinas, com nítida inspiração no fascismo italiano. Assim, a Constituição de 1937 determinou a obrigatoriedade do ensino cívico, ao lado da educação física e dos trabalhos manuais, em todas as escolas primárias, normais e secundárias, públicas e privadas, sem o que não poderiam ser autorizadas ou reconhecidas. O ER foi mantido, mas com uma cláusula de dispensa mais clara do que qualquer outro texto legal, antes e depois: essa disciplina não poderia constituir objeto de obrigação dos mestres ou professores, nem de frequência compulsória por parte dos alunos.

Logo depois da deposição de Vargas, em outubro de 1945, e com ele o fim do Estado Novo, o presidente provisório José Linhares promoveu mudanças na legislação do ensino secundário, suprimindo os elementos mais ostensivamente inspirados no fascismo. Enquanto isso, a Assembléia Constituinte desenvolveu seus trabalhos, nos quais a Igreja Católica usufruiu de plena hegemonia, em suas demandas históricas, de modo que a Constituição de 1946 teve um artigo contemplando o ER, mas sem especificar o nível nem a modalidade. Ficou implícito, portanto, seu possível oferecimento também no nível médio.

Esse foi o quadro no qual se deu a discussão, a tramitação e a promulgação da Lei de Diretrizes e Bases da Educação Nacional (LDB), sancionada pelo presidente João Goulart, em 20 de dezembro de 1961 (lei no 4.024). A lei manteve a norma constitucional de obrigatoriedade do ER nas escolas públicas, mas a EMC foi reduzida à expressão mais simples. Se aquele deveria ser disciplina do currículo, esta nem mesmo prática educativa deveria ser, apenas algo a se levar em conta na organização do ensino médio. 
A ditadura empresarial-militar de 1964 propiciou à EMC assumir posição proeminente na política educacional, sobre o que voltarei a tratar no próximo item. Fica, por enquanto, o registro dessa recuperação da paridade $\mathrm{ER} \Leftrightarrow \mathrm{EMC}$, que só veio a ser quebrada, em proveito da primeira disciplina, no período chamado de redemocratização, iniciado em 1986.

Um fator incidente sobre o ER foi a grande mudança do campo religioso: desde a década de 1960, o crescimento de adeptos de igrejas evangélicas cresceu exponencialmente, em detrimento do catolicismo, o que levou a Igreja Católica a reações de ordens diversas. Uma delas foi propor uma concordata entre o Vaticano e o Estado brasileiro, o que não existiu nem mesmo quando o catolicismo era a religião oficial do Império. Esse acordo foi firmado em maio de 2007, aprovado pelo Congresso Nacional e homologado pelo presidente Lula pelo decreto n⿳ำ 7.107, 11 de fevereiro de 2010.

O Artigo 11 da concordata diz que o ER católico e de outras confissões religiosas, de matrícula facultativa, constitui disciplina dos horários normais das escolas públicas brasileiras de ensino fundamental. Esse artigo contraria, essencialmente, o Artigo 33 do texto reformado da LDB-96, o qual determina que o conteúdo dessa disciplina seja estabelecido pelos sistemas de ensino (federal, estaduais e municipais), depois de ouvidas entidades civis constituídas pelas diversas confissões religiosas. Assim, pode não haver ensino religioso católico, nem de confissão específica alguma. Se esse conteúdo for de caráter histórico, sociológico ou antropológico, como pretendem certas correntes de opinião, ou um extrato das doutrinas religiosas conveniadas, o resultado dependerá da composição política de tais entidades civis. Estava, assim, institucionalizado o conflito no campo religioso, dentro e fora do segmento católico.

No primeiro mandato da presidenta Dilma Rousseff, houve um ostensivo aparelhamento religioso no Ministério da Educação, no que se refere à elaboração da Base Nacional Comum Curricular (BNCC). Apesar de disciplina facultativa, o ER foi erigido a área de estudo, cuja programação foi entregue ao Fórum Nacional Permanente do Ensino Religioso (Fonaper), organização não governamental do segmento católico. As vicissitudes decorrentes do impeachment de Dilma e a posse do vice Temer não impediram que o Conselho Nacional de Educação confirmasse a orientação daquele grupo de pressão religiosa.

Além do ER, a BNCC pretendeu ser uma espécie de EMC interconfessional, evocando, em seu proveito, a qualificação daquela disciplina, pela Lei no 9.475, de 22 de julho de 1997, que introduziu na segunda LDB o ER como parte integrante da formação básica do cidadão CUNHA (2016). Partiu, então, para apresentar todas as religiões como fundamento para as "competências específicas" que se pretendia promover no ensino fundamental: "Debater, problematizar e posicionar-se frente aos discursos e práticas de intolerância, discriminação e violência de cunho religioso, de modo a assegurar os direitos humanos no constante exercício da cidadania e da cultura de paz" (BNCC, p. 437). Como se fosse possível entender a ação do campo religioso sobre o campo político, a 
partir do campo religioso, a BNCC definiu como uma das "habilidades" previstas para o $8^{\text {o }}$ ano do ensino fundamental (alunos de 13 anos de idade):

Discutir como filosofias de vida, tradições e instituições religiosas podem influenciar diferentes campos da esfera pública (política, saúde, educação, economia). Debater sobre as possibilidades e os limites da interferência das tradições religiosas na esfera pública. Analisar práticas, projetos e políticas públicas que contribuem para a promoção da liberdade de pensamento, crenças e convicções (BNCC, p. 457).

Acionado por ação movida pelo Ministério Público a respeito da inconstitucionalidade do artigo 11 da concordata, o Supremo Tribunal Federal decidiu a favor dos termos desse acordo internacional, ou seja, que é lícito (mas não obrigatório) que o ER seja ministrada na modalidade confessional.

Tudo somado, pode-se concluir que, no período republicano, as relações entre o ER e a EMC estavam em sintonia, embora oscilante (CUNHA, 2007). A EMC foi instituída em 1925 e suprimida em 1931 em proveito do ER, que não saiu mais das determinações legais, inclusive constitucionais dos currículos escolares - primeiro do ensino primário, depois do $1^{\underline{0}}$ grau/fundamental. A EMC foi recuperada pelo Estado Novo, para cair junto com esse regime político. Novamente recuperada pela ditadura empresarial-militar, e de novo relegada, ela tende a voltar no governo Jair Bolsonaro segundo duas vias, que serão focalizadas nos próximos itens.

\section{Regeneração moral via disciplina}

No início da década de 1960, formou-se na Escola Superior de Guerra uma corrente de pensamento que defendia a inclusão dos valores morais e espirituais entre os Objetivos Nacionais Permanentes. Após o golpe de Estado de 1964, a moral e a religião passaram a fazer parte da doutrina da ESG, como fatores da expressão psicossocial do Poder Nacional.

A ideia subjacente era que a sociedade brasileira estaria se degenerando devido à ação do materialismo marxista sobre as nossas mais caras tradições democráticas e cristãs. Para regenerar a sociedade, impunha-se o ensino da moral e do civismo em todas as escolas. Mas, a inserção dessa disciplina nos currículos escolares não foi fácil para os pedagogos da ditadura, pois o Conselho Federal de Educação resistiu, alegando que bastava a já existente Organização Social e Política do Brasil. Essa resistência foi vencida pela Junta Militar que assumiu o poder logo após o Ato Institucional no 5 (AI-5), ao promulgar o Decreto-lei no 869, em 12 de setembro de 1969. Ele determinou a inserção dessa disciplina nos currículos de todos os níveis e modalidades de ensino do País, tanto no setor público quanto no setor privado (LEMOS, 2011).

Apoiando-se nas tradições nacionais, a EMC teria por finalidade: a) a defesa do princípio democrático, através da preservação do espírito religioso, da dignidade da pessoa 
humana e do amor à liberdade com responsabilidade, sob a inspiração de Deus; b) a preservação, o fortalecimento e a projeção dos valores espirituais e éticos da nacionalidade; c) o fortalecimento da unidade nacional e do sentimento de solidariedade humana; d) o culto à Pátria, aos seus símbolos, tradições, instituições, e aos grandes vultos de sua história; e) o aprimoramento do caráter, com apoio na moral, na dedicação à família e à comunidade; f) a compreensão dos direitos e deveres dos brasileiros e o conhecimento da organização sócio-político-econômica do País; g) o preparo do cidadão para o exercício das atividades cívicas, com fundamento na moral, no patriotismo e na ação construtiva visando ao bem comum; h) o culto da obediência à lei, da fidelidade ao trabalho e da integração na comunidade (Decreto-lei no 869/1969, Art. $2^{\circ}$ ).

Essa disciplina seria ministrada em todos os níveis de ensino, inclusive no superior, onde assumiria a forma dos estudos de problemas brasileiros (EPB). Os programas, para todos os níveis, seriam elaborados pelo Conselho Federal de Educação, com a colaboração da Comissão Nacional de Moral e Civismo, com seis membros nomeados pelo presidente da República, dentre pessoas dedicadas à causa.

Enquanto os setores da Igreja Católica comprometidos com os movimentos populares e orientados pelo Concílio Vaticano II eram reprimidos pela ditadura e seus aliados, não faltaram clérigos que colaboraram com os militares na luta contra o comunismo ateu. $\mathrm{Na}$ área de educação, inclusive nas instituições católicas, o mais importante deles foi Luciano Cabral Duarte, arcebispo de Aracajú.

Não foi, portanto, por coincidência que o parecer 94/71, do CFE, normatizando a EMC, aprovado em 4 de fevereiro de 1971, tenha sido relatado justamente por ele. Apesar do parecer do arcebispo-conselheiro proclamar que a EMC deveria ser aconfessional, isto é, não vinculada a nenhuma religião e a nenhuma igreja, a incorporação da doutrina tradicional do catolicismo não era sequer disfarçada. O parecer proclamava que a religião era a base da moral a ser ensinada. Para escapar do paradoxo, o arcebispo Duarte lançou mão do conceito de religião natural, isto é, aquela que levaria ao conhecimento de Deus pela luz da razão.

Na prática, a EMC foi lugar de emprego preferencial para religiosos e militares, estes principalmente nos cursos superiores. ${ }^{2}$ No entanto, alguns professores conseguiam, à custa de artifícios, contornar os programas oficiais e desenvolver com os alunos atividades pertinentes de resistência ideológica.

A transição para a democracia levou a EMC a uma lenta agonia, ao contrário do fim do Estado Novo, quando ela foi extinta imediatamente após a deposição de Vargas. O processo longo, tortuoso e contraditório da transição política, desde o início da década de 1980, permitiu-lhe uma surpreendente sobrevida. Apesar de projeto de lei nesse sentido ter sido apresentado ainda no governo Sarney a Lei no 8.663 foi sancionada por Itamar Franco em 14 de junho de /1993. Ela revogou o Decreto-lei nº. 869/69 e determinou que a carga horária dessa disciplina, bem como seu objetivo formador de cidadania e de conhecimentos da realidade brasileira fossem incorporados às disciplinas da área 
de ciências humanas e sociais, a critério de cada instituição educacional. Como a EMC foi tratada de forma genérica, a decisão valeu também para os EPB.

Disciplina extinta deixou saudades nos setores conservadores, que reivindicaram sua volta. Pesquisa realizada por Daniela Patti do Amaral (2007) identificou 13 projetos de lei apresentados por deputados e senadores no período 1997/2006, que procuravam reintroduzir a EMC nas escolas ou inserir disciplinas que contemplassem a ética e a cidadania, em busca do resgate de valores supostamente perdidos pela sociedade. Alguns projetos foram arquivados, outros rejeitados.

Selecionei como exemplo dramático o Projeto de Lei da Câmara nº 722/2003, de autoria do deputado Frankembergen Galvão Da Costa (PTB-RR), delegado de Polícia, bacharel em Teologia e pastor da Assembleia de Deus, que foi reapresentado na legislatura seguinte com o n⿳0 6.570/2006. O projeto foi rejeitado pela Comissão Educação e Cultura nas duas tentativas, sendo, então, definitivamente arquivado em 2004. Vejamos em que consistia o projeto, igual nas duas apresentações.

A LDB deveria incluir nos currículos do ensino fundamental e do médio a Educação para a Moral e o Civismo, voltada para o resgate e a consolidação dos valores morais, patrióticos e sociais. Ele considerou a extinção da EMC foi feita de forma violenta, sem nada deixar no lugar. Rejeitando a identificação com o militarismo da disciplina antecessora, o pastor-delegado-deputado esclareceu que seu projeto de lei visava à preservação da pátria e dos seus símbolos. Ao transmitirem um bem maior, eles orientariam os alunos no "sentido de amor ao próximo, de Justiça e a tranquilidade na garantia do povo brasileiro, e respeito às instituições". Assim, a educação básica atuaria na "difusão de valores fundamentais ao interesse social, aos direitos e deveres dos cidadãos, de respeito ao bem comum e à ordem democrática, através da preservação do espírito religioso, da dignidade da pessoa humana e do amor à liberdade com responsabilidade, sob a inspiração de Deus" (PLC nº 6.570/2006, justificação).

Outros projetos de lei estão em tramitação no Congresso Nacional com o objetivo de reintroduzir a EMC no currículo da educação básica, sob diversos títulos, com um componente predominantemente religioso, explícito ou implícito, no texto do projeto e/ ou na justificativa. A ética que faltaria no povo brasileiro é a defendida pelas religiões, especialmente as da vertente cristã.

O mais avançado na tramitação teve origem no Senado. Foi o de $\mathrm{n}^{0}$ 2/2012, proposto por Sérgio Souza (MDB-PR), ${ }^{3}$ que obteve rápida aprovação, sendo enviado à Câmara dos Deputados no mesmo ano, onde recebeu o no 4.744/2012. Ele pretende inserir no currículo do ensino fundamental a disciplina cidadania, moral e ética, e, no ensino médio, a disciplina ética social e política. Menos ostensivamente religioso do que outros projetos, o senador paranaense previu, também, a inserção das disciplinas filosofia e sociologia no ensino médio, de modo que o projeto resultou um mix peculiar, no qual o pensamento crítico coroaria a ideologia. ${ }^{4}$ A justificativa do senador é esclarecedora de sua motivação: 


\begin{abstract}
Estou convencido de que, dessa forma, estaremos oferecendo a nossa sociedade instrumentos para o fortalecimento da formação de um cidadão brasileiro melhor, por um lado, pela formação, ensinando conceitos que se fundamentam na obediência a normas, tabus, costumes ou mandamentos culturais, hierárquicos ou religiosos; por outro lado, pela formação ética, ensinando conceitos que se fundamentam no exame dos hábitos de viver e do modo adequado da conduta em comunidade, solidificando a formação do caráter; e finalmente para sedimentar o exercício de uma visão crítica dos fatos sociais e políticos que figuram, conjunturalmente, na pauta prioritária da opinião pública, oferecendo aos jovens os primeiros contatos com as noções de democracia, sem caráter ideológico, ensinando-o a construir seu pensamento político por sua própria consciência (PLS nํ2/2012, justificação, grifos meus).
\end{abstract}

Numerosos projetos de reforma da LDB foram apensados ao projeto de Sérgio Machado, até o fim de julho de 2019, quando da última tramitação registrada pelo autor deste texto, de modo que será necessária a elaboração de um substitutivo. Na atual legislatura, ele exerce o mandato de deputado pelo mesmo estado e partido. É um caso raro de parlamentar que deu entrada em projeto numa casa do Congresso e estará na outra para defendê-lo.

Vale a pena registrar a tentativa de inclusão da EMC no currículo das escolas de educação infantil e do ensino fundamental do Distrito Federal, como conteúdo transversal. O projeto de lei do deputado distrital Raimundo Ribeiro (PPS) foi aprovado pela Câmara Distrital, mas vetada pelo governador Rodrigo Rollemberg (PSB), com a justificativa de que questões curriculares não são da competência do Poder Legislativo. A Câmara Distrital derrubou o veto e promulgou a lei $n^{\circ}$ 6.122, em $1^{0}$ de março de 2018. No entanto, o Conselho Distrital de Educação manifestou-se contrário à Lei, por ela invadir suas atribuições. Com essa base argumentativa, ação movida pelo Governo do DF foi acolhida pelo Conselho Especial do Tribunal de Justiça que, em julho de 2019, declarou a Lei inconstitucional.

A sinalização ao governo Bolsonaro nessa matéria veio no Manifesto à Nação da Frente Parlamentar Evangélica, que o apoiava, divulgado quatro dias antes do segundo turno, ou seja, em 24 de outubro de 2018. Além de reivindicar, como aquele candidato, Estado mínimo, privatização das empresas estatais e reforma da previdência, os parlamentares evangélicos exigiam uma revolução na educação. A escola deveria funcionar sem ideologia e sem partido, nem admitir a ideologia de gênero, que teria sido "inventada" pelo Partido dos Trabalhadores e demais frações da esquerda autoritária para subverter os valores e princípios da civilização, condição prévia para instituir uma ditadura, escravizando as consciências pela força do Estado.

No que diz respeito ao nosso tema, ${ }^{5}$ o manifesto foi menos enfático na preservação dos valores cristãos e na defesa da família, como em tantos outros pronunciamentos similares. No entanto, enfatizou o direcionamento moral e cívico do conteúdo das disciplinas da educação básica, como na passagem abaixo: 


\begin{abstract}
devemos instituir o Ensino Moral como conteúdo transversal em todas as disciplinas, visando a formação e sustentabilidade moral, ética e cívica das gerações. Difundir os mais elevados e profundos princípios e valores da Civilização. Universalizar o respeito à vida da pessoa humana individual. (...) Universalização do amor à Pátria, aos Símbolos Nacionais, aos Heróis Nacionais e demais manifestações que agem no plano simbólico. O ensino formal como instrução pública é essencial, contudo, de pouca valia tem se não conseguir transmitir e incutir nas crianças, adolescentes e jovens algo imaterial como o espírito reto na direção da moralidade. Não há grande nação e grande Estado sem o Ensino Moral transversal, que faz a liga da cidadania, e cria resistências contra o crime organizado em todos os setores da vida nacional. Universalização do amor à Pátria, aos Símbolos Nacionais, aos Heróis Nacionais e demais manifestações que agem no plano simbólico (Manifesto 2018, p. 55-56).
\end{abstract}

Não reivindicou a criação de disciplina, como a maioria dos projetos de lei apresentados no Congresso Nacional, mas um conteúdo transversal, isto é, que permearia todas as disciplinas e atividades escolares, na linha da lei aprovada no Distrito Federal sete meses antes. O ER não constou da pauta de reivindicações, já que os evangélicos estão divididos nessa questão - umas igrejas são favoráveis, outras contrárias à existência dessa disciplina nas escolas públicas.

Iniciado o governo Bolsonaro, seu primeiro ministro da Educação, Ricardo Velez Rodrigues, protagonizou um ato sem precedentes, nem mesmo na ditadura empresarial-militar, envolvendo atividades cívicas nos estabelecimentos escolares. Em 25 de fevereiro de 2019, enviou mensagem a todas as escolas públicas e privadas do País, pedindo que os alunos fossem perfilados às segundas-feiras, e cantassem o Hino Nacional. Para completar, deveria ser lida a carta do ministro com o lema da campanha de Bolsonaro: Brasil acima de tudo, Deus acima de todos. A gravação dos eventos deveria ser enviada ao Ministério, procedimento consistente com o reivindicado pelo movimento Escola sem Partido, o que resultaria, na prática, no mais ostensivo partidarismo.

Houve reação generalizada, inclusive de governadores, da esquerda à direita, assim como da imprensa, com algumas secretarias informando o ministro de que o hino já era cantado regularmente, e a gravação em vídeo, sem autorização de cada pai/mãe ou responsável, seria contrária ao disposto no Estatuto da Criança e do Adolescente. No dia $1^{\circ}$ de março seguinte, o ministro suspendeu o pedido, alegando problemas técnicos de armazenamento e segurança do material gravado.

Ainda é incerto o destino da EMC. O projeto Sérgio Souza, o mais avançado na tramitação, tem redação suficientemente ampla para abarcar demandas variadas, podendo pender tanto para a inserção dessa disciplina na versão reivindicada pelos saudosos da ditadura empresarial-militar quanto (menos provavelmente) da educação em direitos humanos, conforme concebida e regulamentada, em termos democráticos e laicos, pelo parecer do Conselho Nacional de Educação CP n⿳o 8/2012, seguido da resolução CP no 1/2012. Lamentavelmente, essa norma não teve eficácia. 


\section{Militarização para controle social}

Escolas públicas de educação básica mantidas e dirigidas por instituições militares são antigas no Brasil. Começaram por razões assistenciais, amparar os órfãos de soldados mortos na guerra da Tríplice Aliança; e prosseguiram por razões corporativas, não apenas nas Forças Armadas, mas, também, nas Polícias Militares e nos Corpos de Bombeiros Militares estaduais. Nos últimos anos, estas foram erigidas em paradigmas de escolas públicas destinadas ao controle social, especialmente dos setores populacionais tidos como perigosos, isto é, os mais pobres, função atribuída ao trabalho pelas escolas de aprendizes-artífices e ao trabalho e à religião pela pedagogia salesiana.

Para evitar as frequentes confusões resultantes do adjetivo militar atribuído a instituições diferentes, vale a pena começar por distingui-las.

Colégios Militares: são instituições pertencentes ao Exército Brasileiro, que admitem alunos mediante concurso combinado com sorteio, cobram mensalidades e atuam no segundo segmento do ensino fundamental e no ensino médio. Há 12 estabelecimentos de ensino com o nome de colégios militares (14 se incluirmos a Fundação Osório e o Colégio Brigadeiro Newton Braga), que matricularam cerca de 13 mil alunos em $2018 .{ }^{6}$

Escolas preparatórias às escolas de formação de oficiais: existe uma para cada Força, a Escola Preparatória de Cadetes do Exército (Campinas, SP), a Escola Preparatória dos Cadetes do Ar (Barbacena, MG) e o Colégio Naval (Angra dos Reis, RJ). O ingresso nelas se dá mediante concurso para alunos concluintes do ensino fundamental, que cursam o ensino médio e recebem instrução militar.

Os concluintes do primeiro segmento do ensino fundamental nos colégios militares podem ingressar no ensino médio na mesma instituição ou se candidataram às escolas preparatórias às instituições de formação de oficiais. Os concluintes desses colégios e os do ensino médio comum, tanto em estabelecimentos públicos quanto privados, podem se candidatar diretamente a essas instituições, que são a Academia Militar das Agulhas Negras (RJ), a Academia da Força Aérea (Pirassununga, SP) e a Escola Naval (Rio de Janeiro, RJ), indiferentemente, ou se desligar, retornando à vida civil e tomando rumos indeterminados.

Os colégios militares já nada têm hoje de funções apenas corporativas: escolarização de filhos de membros das Forças Armadas em condições privilegiadas e celeiro de candidatos às escolas preparatórias. O oferecimento de educação básica de alta qualidade intelectual pelos colégios militares e pelas escolas preparatórias é amplamente reconhecido. Todavia, a eficácia do aliciamento está para ser comprovada, principalmente em vistas dos custos reais de tais estabelecimentos de ensino, que, ademais, estão para ser devidamente calculados.

Escolas das Polícias Militares e dos Corpos de Bombeiros Militares são uma espécie de versões estaduais dos colégios militares do Exército: ministram o segundo segmento do ensino fundamental e o ensino médio a filhos dos membros dessas corporações, aceitando, também, candidatos sem esse predicado, em geral mediante sorteio combinado 
com concurso. Na maior parte dessas escolas, os docentes e o pessoal de apoio são fornecidos pelas secretarias estaduais de educação, atuando sob o comando - a expressão é mesmo essa - de oficiais PM e bombeiros. A exceção fica com a PM de São Paulo, que fez convênio com a instituição confessional Cruz Azul para a parte da educação geral. A tabela abaixo, construída com base nas informações disponíveis nos portais dos estados de Minas Gerais, São Paulo e Rio de Janeiro, permite constatar as diferentes antiguidades e dimensões das suas redes paralelas.

\section{Tabela 1- Escolas de PM e CBM}

\begin{tabular}{c|c|c}
\hline Unidades da Federação & Ano da $\mathbf{1}^{\mathbf{a}}$ unidade escolar & $\mathbf{n}^{\mathbf{0}}$ de unidades em 2019 \\
\hline MG & 1950 & 30 \\
SP & 1978 & 13 \\
RJ & 2006 & 3 \\
\hline
\end{tabular}

Vemos que os três estados do Sudeste (não foi localizada escola desse tipo no Espírito Santo) totalizaram 46 escolas de PM e CBM, sendo que Minas Gerais se destaca pelo número e pela antiguidade da primeira escola instalada. Enquanto que esse estado instalou a sua em 1950, o Rio de Janeiro só fez o mesmo mais de meio século depois, sendo que sua terceira escola foi inaugurada no início do ano letivo de 2019.

Os estabelecimentos de educação básica militares federais e estaduais têm parte de suas despesas cobertas pelas contribuições das famílias, que, ademais, assumem as despesas com uniformes diferenciados. As vagas postas em concurso são disputadas. No caso dos colégios militares, existem cursinhos especializados nessa clientela, com aulas presenciais e a distância. Seu prestígio é elevado, resultado dos recursos materiais e organizacionais que possuem, ${ }^{7}$ reforçado pela ideia, bastante difundida na população, de que a disciplina militar forma bem o caráter das crianças e dos jovens, a começar pelo controle dos corpos: cabelos cortados e presos, proibição de tatuagens e piercings, saias abaixo dos joelhos; namoro e manifestações de afeto proibido na escola e nos arredores. Rituais disciplinadores, como exercícios de ordem unida e continência prestada a militares e professores civis, distinguem tais escolas das comuns.

Nos estabelecimentos militares federais, os professores civis usufruem remuneração significativamente superior à de seus colegas das redes estaduais, e contam com a colaboração de equipes de apoio psicológico e pedagógico, algo inexistente naquelas. Como os alunos de muito baixo rendimento escolar e alta indisciplina podem ser excluídos, o resultado obtido pelos colégios militares do Exército são superiores às das escolas das redes estaduais (Ideb médio 6,5 contra 4,1), mas são superados por outros estabelecimentos federais civis, como se vê no quadro abaixo, cujos dados foram acessados no 
Instituto Nacional de Estudos e Pesquisas Educacionais Anísio Teixeira, e gentilmente cedidos por Marcela Moraes de Castro, doutoranda do PPGE/UFRJ.

\section{Tabela 2 - Índice de desenvolvimento da educação básica (8/9 anos do ensino fundamental) de estabelecimentos de ensino federais na cidade do Rio de Janeiro - 2016}

\begin{tabular}{l|c}
\hline Estabelecimentos de ensino & DEB \\
\hline Colégio Militar do Rio de Janeiro & 7,0 \\
\hline Fundação Osório & 5,5 \\
\hline Colégio Brigadeiro Newton Braga & 5,6 \\
\hline Colégio Pedro II - Unidade Centro & 7,1 \\
\hline Colégio de Aplicação da UFRJ & 6,9 \\
\hline
\end{tabular}

Os colégios mantidos e dirigidos pelo Exército e pela Aeronáutica têm índices bem diferentes, variando de 5,5 a 7,0, enquanto os dois estabelecimentos civis estão praticamente empatados com aquele no índice mais elevado. ${ }^{8}$ Essas informações são suficientes para demolir a imagem dos colégios militares como bastiões exclusivos da excelência no setor público.

Nos estabelecimentos militares, tanto nos federais como nos estaduais, a educação moral e cívica é valorizada com este ou outro nome. Os conteúdos das disciplinas comuns às demais escolas são, também, influenciados pela ideia da regeneração moral da sociedade. A História do Brasil é especialmente visada, com o emprego de livros que apresentam o golpe militar de 1964 como um movimento revolucionário que livrou o Brasil do perigo comunista.

O governador de Goiás Marconi Perillo, que exerceu quatro mandatos, desenvolveu uma política educacional que apontou um caminho assumido pelos de outras unidades da Federação, assim como pelo Governo Federal na gestão Jair Bolsonaro. Inicialmente, ele priorizou a criação de colégios da PM goiana no interior do estado, com um objetivo que destoava dos similares. Em seguida, extrapolou o objetivo corporativo para prevenir o desvio de jovens das camadas populares para o crime.

A instalação de colégios militares nas cidades do interior do estado, do mesmo modo que na capital, constitui medida de segurança preventiva da mais alta eficácia, tendo em vista que, a par da educação de boa qualidade ministrada, não se podem desconhecer os valores da disciplina e da ordem, cultivados no seio dessas unidades escolares, na formação da juventude, especialmente, nos tempos atuais, em que a ausência de limites nesse segmento social responde em grande parte, como se sabe por seu lamentável extravio para as hordas do crime, daí que essa medida vem sendo reclamada pela própria população, por meios formais de participação, inclusive, mediante listas de assinaturas (Projeto de Lei nº 83/2013 - Goiás, apud ALVES et al., 2018, p. 275). 
Em 2015, o governador goiano definiu outro modelo de escola militarizada. Ao invés de ser o estabelecimento policial militar que recebia docentes da rede estadual, agora era a escola da rede que recebia os PM. No contexto de uma greve de professores, o governador anunciou a enquadramento militar de escolas da rede estadual como uma espécie de castigo aos docentes grevistas (ALVES et al., 2018, p. 276). Entre 2015 e 2018, 51 escolas da rede estadual passaram a se chamar colégios estaduais da Polícia Militar, afetos à Coordenação dos colégios militares, paralelamente às demais. (Idem, p. 278)

Cada Colégio Estadual da Polícia Militar goiana é dirigido por um coronel PM, secundado por um major, que auferem rendimentos adicionais aos seus vencimentos, na forma de gratificações, o que cria uma duplicidade no interior de cada estabelecimento de ensino, coincidente com a hierarquização interna, na qual o corpo docente civil encontra-se subordinado ao militar.

A dissertação de mestrado de Rafael José da Costa Santos (2016) mostrou que, além da demanda por esse modelo de escola, da parte de prefeitos e setores da população, houve, também, resistência não divulgada pela imprensa, tanto de instituições da sociedade civil organizada quanto de estudantes, inclusive nos movimentos de ocupação, intensos naquele estado. Uma das vozes silenciadas assim protestou: "Não queremos exclusão. Não queremos mensalidades, uniformes pagos, taxas de matrícula. Não queremos militares impondo as metas do governo sobre professores e estudantes" (Idem, p. 38-39).

Nas eleições de 2018, vários candidatos a governador lançaram mão da militarização das escolas públicas como apelo de campanha. O candidato a presidente da República Jair Bolsonaro fez o mesmo, prometendo criar um colégio militar em cada capital de estado, uma medida parcialmente inócua (quase metade das unidades da Federação já os tinham). Eleito presidente, ele promoveu reforma administrativa no Ministério da Educação, que incluiu uma inédita Subsecretaria de Fomento às Escolas Cívico-Militares, logo ocupada por mulheres coronéis do Corpo de Bombeiros do Distrito Federal. Em 2019, a Subsecretaria foi ocupada por um coronel do Exército, transferido do Colégio Militar do Rio de Janeiro.

No dia 5 de setembro de 2019, o Ministério da Educação anunciou o Programa Nacional das Escolas Cívico-Militares (Pecim), instituído pelo Decreto no 10.004, da mesma data, com a meta de 216 estabelecimentos até 2023, ao ritmo de 54 por ano. Não seriam construídas novas escolas, pois as unidades da Federação e os municípios que aderissem ao programa indicariam a escola das respectivas redes para adotar o modelo das escolas cívico-militares (Ecim), com 500 a 1.000 alunos, do $6^{\circ}$ ao $9^{\circ}$ ano do ensino fundamental e/ ou do ensino médio; situadas, preferencialmente, em regiões de maior vulnerabilidade social, elas adotariam os modelos de gestão dos colégios militares do Comando Exército, das polícias militares e dos corpos de bombeiros militares. O Ministério destinaria recursos financeiros para o pagamento de gratificações a militares inativos, para atuarem nas áreas de gestão educacional, didático-pedagógica e administrativa. 
Um dos requisitos de inclusão de escola estadual no programa é a realização de consulta pública formal e de caráter vinculante à comunidade escolar, com o objetivo de aprovar o modelo Ecim. Parece que essa condição poderá ser dispensada, a julgar pelo pronunciamento do presidente Bolsonaro na cerimônia de lançamento do programa. Ao comentar recusa de modelo similar no Distrito Federal, assim disse ele: "Vi que alguns bairros tiveram votação e não aceitaram. Me desculpe, não tem que aceitar não, tem que impor. Não queremos que essa garotada cresça e vai ser, no futuro, um dependente até morrer de programas sociais do governo" (Agência Brasil, 5/9/2019).

A socialização política foi difusamente apresentada no decreto de criação do Pecin (desenvolvimento de comportamentos, valores e atitudes, com vistas ao desenvolvimento pleno do aluno e ao seu preparo para o exercício da cidadania), mas foi claramente explicitada no momento mesmo do lançamento do programa, pelo próprio presidente Bolsonaro: "tem que botar na cabeça dessa garotada a importância dos valores cívicos-militares, como tínhamos há pouco no governo militar, sobre educação moral e cívica, sobre respeito à bandeira" (Idem).

\section{Dessintonia conflitante}

No primeiro item deste artigo apresentei a sintonia oscilante entre o ER e a EMC em décadas passadas. Trato, aqui, da dessintonia que se desenvolve desde a Assembleia Nacional Constituinte de 1987/1988. Começou aí um movimento pela laicidade da educação pública sem precedentes na história do Brasil, que cresceu, desde então, impulsionado pela reação às manobras das igrejas Católica e evangélicas para transformar as escolas públicas de ensino fundamental em arena de disputa pela hegemonia no campo religioso. Não bastasse isso, a concordata entre o governo brasileiro e o Vaticano, homologada em 2010, abriu uma frente de disputa entre a corrente que defendia o ER confessional e a que o queria inter/pluri/não confessional. Ambas encontraram respaldo jurídico no confuso e contraditório direito público brasileiro.

A atuação política das igrejas cristãs apresenta, ademais, convergências e divergências relevantes. Elas convergem no combate ao que entendem ser a ideologia de gênero nas escolas públicas e privadas, mas divergem no apoio ao movimento Escola sem Partido - as igrejas evangélicas pentecostais o apoiam, enquanto que a Igreja Católica desconfia dele, pelo menos sua cúpula dirigente. Divergência similar ocorre diante das políticas econômica, previdenciária e ambiental do governo Bolsonaro e seus correligionários estaduais.

Passando à EMC, vemos que ela é objeto de propostas bem diferentes, uma que defende a especialização disciplinar, versão ora mais ora menos branda da que foi definida pela junta militar em 1969, outra que a deseja transversal, permeando todas as disciplinas do currículo. 
Mais radical do que qualquer dessas vias é a política de implantação das escolas cívico-militares, modelo que tomou forma no estado de Goiás, em 2015, e foi assumida pelo governo Bolsonaro. Ao contrário da implantação da EMC pela especialização disciplinar ou pela transversalidade curricular, trata-se, agora, da segmentação escolar: a adaptação de escolas estaduais e municipais à gestão e à pedagogia militar, mediante convênio com os ministérios da Educação e da Defesa.

Abre-se, então, nova frente de dessintonias, a saber: ministérios com propósitos bem diferentes; controle federal versus controle estadual e/ou municipal, inclusive escanteamento dos conselhos Nacional, estaduais e municipais de educação; pedagogia tendente ao diálogo e à gestão democrática (aliás determinada na LDB) versus pedagogia baseada na hierarquia e no comando; pessoal docente civil estadual e municipal versus pessoal dirigente militar federal e/ou estadual. Resumindo: a pedagogia moderna (de Michel de Montaigne a Paulo Freire, passando por John Dewey) enfatiza o pensamento crítico. A pedagogia da "ordem unida" enfatiza a formação para cumprir ordens sem questionamento: manda quem pode, obedece quem tem juízo, isto é, para evitar punição.

Que efeitos objetivos pode-se esperar desses projetos socializadores? É claro que as políticas educacionais pretendem-se eficazes. Vejamos em que as ciências sociais podem ajudar a entender as vicissitudes do processo socializador. Primeiro, a dimensão objetiva, depois a subjetiva.

Os antropólogos Peter Berger e Thomas Luckmann (1983) mostraram que há dificuldades objetivas para se chegar a uma socialização perfeita, duas das quais são relevantes para o nosso caso: a heterogeneidade do pessoal socializador e a mediação de culturas discordantes (p. 221-228).

Com efeito, é de esperar que o pessoal socializador seja bastante heterogêneo no caso da política de regeneração moral via especialização disciplinar. Quem vai ministrar a EMC na educação básica? Professores especialmente formados para isso? A experiência de implantação dessa disciplina nos anos 1970 sustenta a hipótese de que as dificuldades seriam agora muito maiores do que as de cinco décadas atrás, quando militares e religiosos foram os docentes mais frequentes As tentativas de formação de docentes especializados em EMC (e na versão EPB, para o ensino superior) foram um retumbante fracasso. Os sistemas educacionais públicos são hoje significativamente mais amplos e diferenciados em todos os níveis. As redes privadas, mais reduzidas na educação básica do que naquela época, passaram a adotar sistemas estruturados de ensino que precisam atender a demandas de segmentos das camadas médias que rejeitam padrões moralistas em termos de sexo e gênero, assim como manifestações cívicas autoritárias. Se a opção disciplinar for abandonada em proveito da transversal, a heterogeneidade seria elevada à máxima potência.

Na via da segmentação escolar mediante a criação das escolas cívico-militares, pode-se esperar alguma homogeneidade do pessoal socializador proveniente das Forças Armadas, das Polícias Militares e dos Corpos de Bombeiros Militares, no que diz respeito 
à dimensão mais ostensivamente ideológica do ensino nelas ministrado. Todavia, mesmo desconsiderando, para efeito de raciocínio, que os docentes civis não constituíssem elemento heterogeneizador, a segunda razão objetiva para a produção da socialização defeituosa poderá existir. Trata-se da mediação de culturas discordantes, senão contraditórias. Os alunos das escolas cívico-militares não viverão isolados do mundo, ou quase isso, como os das escolas preparatórias e do Colégio Naval. Se nem esses estão isentos da influência socializadora de agentes não militares e até mesmo anti-militaristas, menos ainda estarão os alunos civis daquelas outras, mais expostos que serão aos meios de comunicação de massa, aos movimentos sociais, às instituições do campo religioso (cada vez mais conflituoso) e outros agentes socializadores, cuja diversidade em termos de valores e padrões de comportamento não estarão alinhados com os propósitos disciplinadores pretendidos pelo Pecim.

Mesmo se concentrarmos nossa atenção nos colégios militares, nas escolas das PM, assim como nas escolas preparatórias de cadetes e o Colégio Naval, não é lícito supor que seus alunos absorvam as normas e os valores que lhe são ensinados, sem levar em conta normas e valores distintos, veiculados no mundo lá fora. Por mais que aqueles estabelecimentos se esmerem nas suas práticas próprias, apenas uma parcela diminuta dos seus egressos segue carreira nas Forças Armadas e nas auxiliares. E não tem cabimento supor que os desistentes sejam reprodutores perfeitos do que aí lhes foi incutido, o que nos remete ao sociólogo Claude Dubar (2005), que chama a atenção para a dimensão subjetiva do processo de socialização. Ele não é unidirecional, pois implica uma transação ou uma negociação constante entre cada indivíduo e os agentes socializadores, não só na infância, mas, também, na vida adulta. "A socialização não é essencialmente o resultado de aprendizagens formalizadas mas o produto, constantemente reestruturado, das influências presentes ou passadas dos múltipos agentes de socialização" (p. 23).

Em suma, é de se esperar que o fracasso das políticas educacionais na socialização política aqui discutida seja ainda maior e mais rápido do que a do período mais tenebroso da ditadura empresarial-militar.

Recebido em:23/11/2019 e Aceito em: 02/12/2019

\section{Notas}

1 Para estudos empíricos voltados para o Brasil, remeto a Schmidt (2001) e ao dossiê sobre esse tema organizado por Kimi et al. (2016).

2 Houve iniciativas de formação de docentes para a EMC, especialmente para os EPB, em cursos de pósgraduação lato senso e mestrado. Ver Lerner (2013) e Cunha (2012). 
3 Ele foi suplente da senadora Gleizi Hoffman. O projeto em foco foi apresentado quando assumiu o posto no lugar da titular, licenciada para ocupar a chefia da Casa Civil no governo Dilma.

4 Essas disciplinas já estavam asseguradas pela Lei 11.684/2008, aprovada quatro anos antes de sua iniciativa legislativa. Terá sido uma espécie de antídoto contra a acusação de reacionarismo?

5 Os evangélicos apresentaram, também, reivindicações para o ensino superior, como a libertação dos professores da pós-graduação, estrito e lato senso, da "repressão" exercida pela Capes.

6 O primeiro Colégio Militar foi criado no Rio de Janeiro, em 1889, no ocaso do Império, para alunos do sexo masculino. Sua instalação demorou tanto que, ao ser inaugurado já não havia órfão de militar falecido em combate no Paraguai, menor de idade. Em 1924 nasceu a Fundação Osório, com idêntica finalidade, mas para os do sexo feminino. Na década de 1990, as duas instituições, como suas co-irmãs, passaram a admitir alunos de ambos os sexos. Por essa razão, a capital carioca é a única cidade que possui dois estabelecimentos de educação básica mantidos e dirigidos pelo Exército. Os colégios militares foram instalados nas capitais (com duas exceções): Rio de Janeiro, Porto Alegre, Fortaleza, Belo Horizonte, Salvador, Recife, Curitiba, Manaus, Brasília, Campo Grande, Juiz de Fora (MG) e Santa Maria (RS). Em 1960, o Ministério da Aeronáutica criou, no Rio de Janeiro, o Colégio Brigadeiro Newton Braga, destinado aos filhos de militares e funcionários civis dessa pasta.

7 A despesa média dos colégios militares do Exército (sem contar os vencimentos do pessoal militar nelas lotado) é considerada o triplo das escolas públicas do mesmo nível de ensino.

8 As unidades descentralizadas do Colégio Pedro II são avaliadas como escolas diferentes, apesar de pertencerem ao mesmo estabelecimento. Elas apresentam Ideb mais baixo do que o da unidade Centro, entre 5,5 e 6,5 .

\section{Referências}

AGÊNCIA BRASIL. Governo lança programa para escolas cívico-militares, Brasília, 05/09/2019. Disponível em: http://agenciabrasil.ebc.com.br/politica/noticia/2019-09/governo-lanca-programa-paraescolas-civico-militares. Acessado em: 15/10/2019.

ALVES, Míriam Fábia; TOSCHI, Mirza Seabra; FERREIRA, Neuza Sousa Rêgo. A expansão dos colégios militares em Goiás e a diferenciação na rede estadual, Revista Retratos da Escola, Brasília, v. 12, n. 23, 2018.

AMARAL, Daniela Patti do. Ética, moral e civismo: difícil consenso. Cadernos de Pesquisa, São Paulo, v. 37, n. 131, p. 351-369, maio/ago. 2007.

Base Nacional Comum Curricular - versão final, Brasília: MEC/SEB, 2018. Disponível em: http:// basenacionalcomum.mec.gov.br/images/BNCC_EI_EF_110518_versaofinal_site.pdf. Acessado em: 18/10/2019.

BERGER, Peter; LUCKMANN, Thomas. A construção social da realidade, Petrópolis: Vozes, 1983.

BRASIL. Decreto-lei nº 869, de 12 de setembro de 1969. Dispõe sobre a inclusão da Educação Moral e Cívica como disciplina obrigatória, nas escolas de todos os graus e modalidades, dos sistemas de ensino no País, e dá outras providências. Brasília, 1969.

BRASIL. Câmara dos Deputados. Projeto de Lei da Câmara no 6.570/2006. Altera a Lei n 9.394, de 20 de dezembro de 1996, que "Estabelece as diretrizes e bases da educação nacional", incluindo no currículo oficial, da rede de ensino, a obrigatoriedade do ensino de Educação para a Moral e o Civismo, e dá outras providências. Brasília, 2006. 
CUNHA, Luiz Antônio. Sintonia oscilante: religião, moral e civismo no Brasil - 1931/1997, Cadernos de Pesquisa, São Paulo, v.37, n.131, pp.285-302, maio/agosto, 2007.

CUNHA, Luiz Antônio. Os Estudos de Problemas Brasileiros na UFRJ: aproximações institucionais. Revista Contemporânea de Educação, Rio de Janeiro, v.7, n.13, 2012.

CUNHA, Luiz Antônio. A entronização do ensino religioso na Base Nacional Curricular Comum. Educação \& Sociedade, Campinas, v.37, n.134, janeiro/março 2016.

DUBAR, Claude. A socialização: construção das identidades sociais e profissionais, São Paulo: Martins Fontes, 2005.

KIMI, Tomizaki; SILVA, Maria Gilvania Valdivino; CARVALHO-SILVA, Hamilton Harley de.

Socialização política e politização entre famílias do Movimento dos Trabalhadores Sem Teto. Educação \& Sociedade, Campinas, v.37, n.137, out./dez., 2016.

LAGROYE, Jacques; FRANÇOIS, Bastien; SAWICKI, Frédéric. Sociologie politique. Paris: Presses de Sciences Po/Dalloz, 2006.

LEMOS, Kaé Stoll Colvero. A normatização da Educação Moral e Cívica (1961-1993). Dissertação (Mestrado em Educação) - Faculdade de Educação, Universidade Federal do Rio de Janeiro, Rio de Janeiro, 2011.

LERNER, Samara Mancebo. A pós-graduação em Estudo de Problemas Brasileiros na UERJ: uma reflexão sociológica sobre um projeto de socialização política no Brasil. Tese (Doutorado em Sociologia) - Instituto de Ciências Sociais, Universidade do Estado do Rio de Janeiro, Rio de Janeiro, 2013.

CÂMARA DOS DEPUTADOS. FRENTE PARLAMENTAR EVANGÉLICA. Manifesto da Frente Parlamentar Evangélica. Brasília, 2018. Disponível em: https://controle.revistaforum.com.br/wp-content/ uploads/2018/10/documento-da-bancada-evangelica.pdf_Acessado em: 09/10/2019.

SANTOS, Rafael José da Costa. A militarização da escola pública em Goiás. Dissertação (Mestrado em Educação), Pontifícia Universidade Católica de Goiás, Goiânia, 2016.

SCHMIDT, João Pedro. Juventude e Política no Brasil. A socialização política dos jovens na virada do milênio. Santa Cruz do Sul: Edunisc, 2001. 